\title{
Electric field analysis of 132kv EPDM insulator and correlation with ageing features
}

DOI:

10.1109/EIC.2013.6554235

Link to publication record in Manchester Research Explorer

\section{Citation for published version (APA):}

Tzimas, A., Zachariades, C., \& Rowland, S. M. (2013). Electric field analysis of 132kv EPDM insulator and correlation with ageing features. In 2013 IEEE Electrical Insulation Conference, EIC 2013/IEEE Electr. Insul. Conf., EIC (pp. 210-214). https://doi.org/10.1109/EIC.2013.6554235

\section{Published in:}

2013 IEEE Electrical Insulation Conference, EIC 2013|IEEE Electr. Insul. Conf., EIC

\section{Citing this paper}

Please note that where the full-text provided on Manchester Research Explorer is the Author Accepted Manuscript or Proof version this may differ from the final Published version. If citing, it is advised that you check and use the publisher's definitive version.

\section{General rights}

Copyright and moral rights for the publications made accessible in the Research Explorer are retained by the authors and/or other copyright owners and it is a condition of accessing publications that users recognise and abide by the legal requirements associated with these rights.

\section{Takedown policy}

If you believe that this document breaches copyright please refer to the University of Manchester's Takedown Procedures [http://man.ac.uk/04Y6Bo] or contact uml.scholarlycommunications@manchester.ac.uk providing relevant details, so we can investigate your claim.

\section{OPEN ACCESS}




\title{
Electric field analysis of $132 \mathrm{kV}$ EPDM insulator and correlation with ageing features
}

\author{
Antonios Tzimas, Christos Zachariades and Simon M. Rowland \\ School of Electrical and Electronic Engineering \\ The University of Manchester \\ Manchester, M13 9PL, UK \\ Antonios.Tzimas@manchester.ac.uk
}

\begin{abstract}
A COMSOL multiphysics electric field analysis of an ethylene-propylene rubber (EPDM) insulator is presented. The $132 \mathrm{kV}$ insulator is an inverted post insulator that is taken from a jumper loop. It has been in service in a severely polluted environment for eight years. The insulator's surfaces are asymmetrically aged with organic dark deposits covering the insulator's surface, and with additional surface markings. The insulator has a manufacturing artifact, known as the mold line, which forms an elongated protrusion along the length of the insulator. This artifact is introduced into the COMSOL model to investigate its effect on the local electrical field. The reason for this study is that the area surrounding the mold line is lighter in color, with markings that suggest discharge activity. The regions of the localized field enhancements are identified and correlated with the ageing features, such as hydrophobicity loss, surface roughness and discoloration observed after eight years in service. A discussion whether the environment or the electric field are dominating the ageing process of the insulator is included.
\end{abstract}

Keywords - component; outdoor insulators; Asymmetrical ageing; COMSOL multiphysics analysis; Ageing; mold line; condition monitoring

\section{INTRODUCTION}

In recent years outdoor composite insulators such as those based on ethylene-propylene rubbers (EPDM) and silicone rubbers $(\mathrm{SiR})$ have been replacing the traditional ceramic and glass ones on HV systems. The main reason is the excellent hydrophobic properties of the composite insulators especially in coastal polluted environments [1]. The number of utilities that are installing composite insulators is increasing [2] as confidence is gained on their performance [3]. Nevertheless composite insulators still have to compete with the rich history and long service life (over 50 years) that ceramic and glass insulators have. Despite the numerous advantages of the composite insulators over the ceramic ones and the resistance of polysiloxanes and ethylene-propylene based rubbers to weathering, composite insulators do age over time [4]. The rate that composite insulators age is dependent upon the environmental conditions such as electrical stress, geographical location, solar and UV radiation, temperature variations, precipitation as well as wind speed and direction [5]. It has been reported that non uniform exposure of composite insulators to environmental stresses has led to asymmetrical ageing between south- and north-faces of both SiR [6] and EPDM [7] transmission line insulators.

The ageing features as well as the environmental stresses of $132 \mathrm{kV}$ EPDM insulators with three different designs are

The authors would like to acknowledge Scottish and Southern Energy for their support of this research. described in more detail in [8]. In this work we investigate the effect that the electrical stress may have on the ageing features observed on the surface of the inverted jumper loop insulator after eight years in service, see Figure 1. The dominating environmental stresses are also correlated with ageing surface features observed.

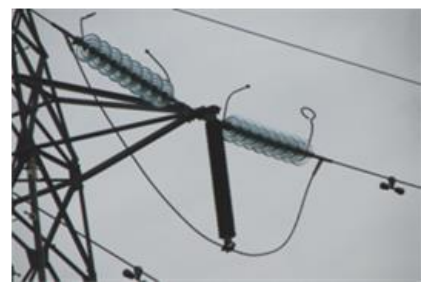

Figure 1: Jumper loop insulator configuration in service.

The four main environmental characteristics at site are:

- High precipitation (1455 $\mathrm{mm}$ per year)

- Low UV radiation, northerly latitude of $56^{\circ}$.

- Strong winds from the Atlantic ocean.

- Saline airborne pollution from the sea locks.

\section{Ageing Features}

For clarity, the sides of the insulator were labeled accordingly; D1, D2, D3 and D4. The D1 and D3 sides have a clearly protruding mold line. The low voltage end is referred to as the top of the insulator, and the bottom part is called the high voltage end. The top face of the shed is the one that is facing the sky and the bottom face is the one facing the ground. The ageing features of the jumper loop insulator are assessed by visual inspections and Hydrophobicity Classification measurements. The compass orientations are provided with the top view of a single shed representation of the insulator in the relevant figures for reference.

\section{A. Visual observations}

Figure 2 shows photographs of the whole insulation string of sides D1 and D3 where the mold lines are located. From these photographs it can be observed that the area 1 or 2 centimeters either side of the mold line is light-colored, forming a strip with high contrast to the dark colored surface that surrounds it. It is also observed, that some light-colored tree-like patterns are defining the light-colored strip along the length of the mold line. The shape of the tree-like patterns 
suggests that these regions have been generated by surface discharges, and in [8] it has been confirmed that the dark colored deposits covering the surface can be removed by discharges under wet and highly conductive conditions. This general ageing pattern is not unique to this site. The lightcolored area in Figure 2 around the mold line of D1 side becomes wider near the HV end, while on the D3 side remains thin across the length of the whole insulator, suggesting a higher surface discharge activity under the wet conditions of the D3 side.

Another macro difference that is observed is the different depths of color between sides D1 and D3. Side D1 is slightly lighter than the D3. This difference in brightness may occur because the orientation of the insulator and the resulting asymmetrical ageing due to natural solar UV light.

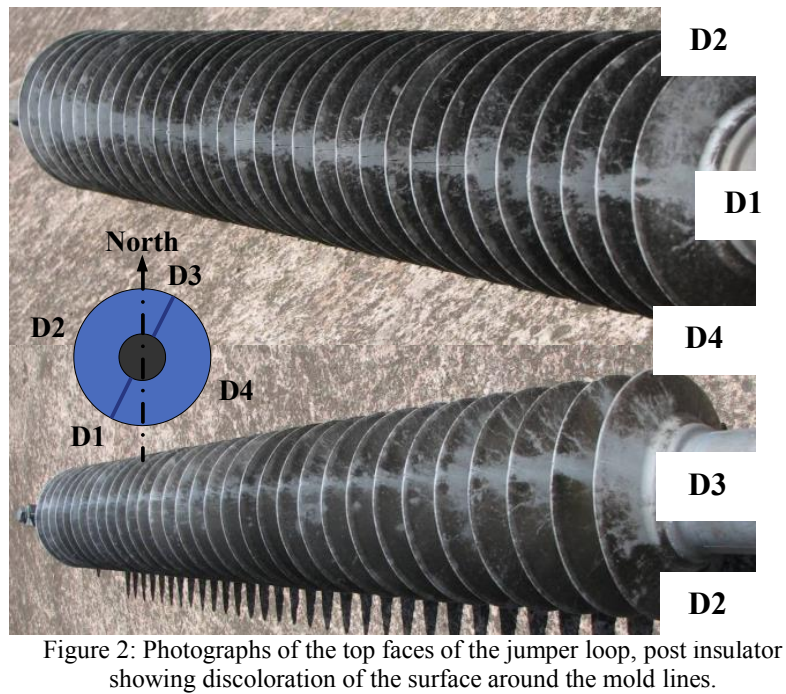

The color of the core near the LV end is dark. On the other hand, the core and adjacent shed area near to the HV end of the post insulator is light color, see Figure 3. This, along with the broadening of the light color strip on the shed's top surface indicates electrical activity (in particular discharges) that keeps the surface clean.

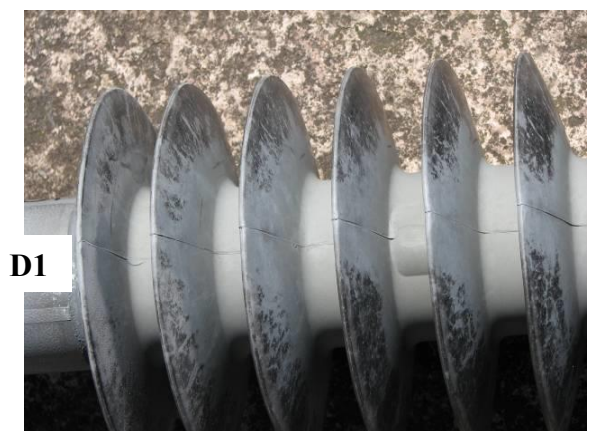

Figure 3: Photograph showing the light colored area adjacent to the core increasing near to the HV end.
The top side and underside of the insulator's sheds are shown in Figure 4. It is observed that there is a significant difference in the contrast of the frequency of appearance of the tree-like markings both on top and underside of the sheds. On the photographs of the D2 side the markings are very thin and spread out, especially on the underside as at the top side there are hardly any. However, on the photographs of the D4 side the markings are wider and denser on both the top and underside of the sheds. According to weather averages [9] there are strong easterly winds blowing to the west.

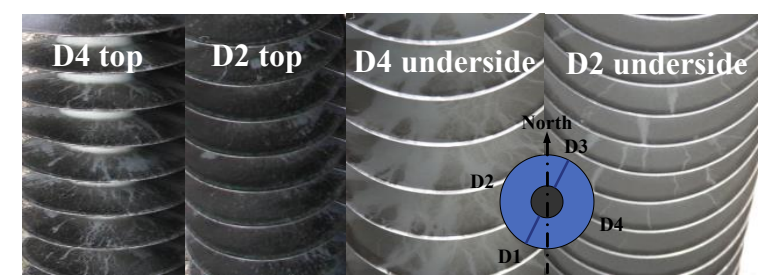

Figure 4: The light colored markings on the top and underside of sheds of D4 and $\mathrm{D} 2$ directions.

It is observed that crazing (rough surface) can be identified around the edge of the sheds of the insulator especially at the more exposed parts, i.e. top sheds, see Figure 5. Crazing is normally associated with solar UV radiation. It should be noted that crazing has not been observed in the area adjacent by the mold line as reported previously in [10]. The reason this is not seen adjacent to the mold line is not clear. It may be the surface morphology of the polymer is different in this location, but it is more likely that it is due to the behavior of moisture under discharge conditions in the location of the protrusion.

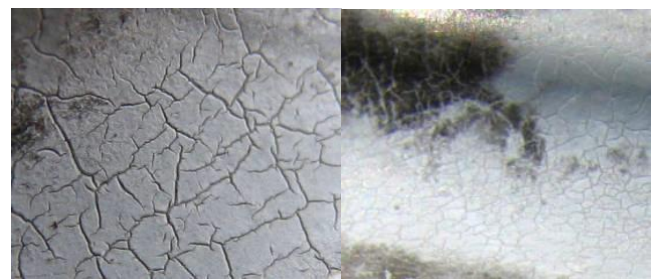

Figure 5: The surface roughness and crazing on the surface of the top shed of the insulator.

\section{B. Hydrophobicity classification}

Measurements have been carried out using hydrophobicity classification (HC) measurement techniques. Due to asymmetrical ageing, the hydrophobicity distribution is non-

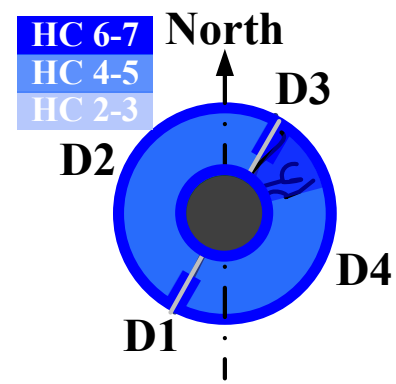


Figure 6: Hydrophobicity Classification representation on a shed looking from the top. The location of the discharge pattern on D4 side is indicated with the darker color lines.

uniform along the insulators length, core and sheds. A summary of the HC [11] measurements is reflected in Figure 6 . The regions where light and dark color contrast existed on the same surface, the light color surfaces were more hydrophilic than the dark color surface, and water films can only exist on the light surface, i.e. they are more easily wettable.

\section{ELECTRIC FIELD ANALYSIS}

The electric field distribution around insulators affects their flashover behavior and can decrease their service life if not controlled properly. Uneven field distribution along the length of the insulator can overstress and ultimately damage parts of the unit as a result of preliminary discharges on the surface which usually take place before flashover. Of particular interest in this case is the electric field distribution around the mold line. The coloring variations on the surface around the mold line area indicate the presence of local electric field enhancement.

\section{A. Insulator Model}

To examine this hypothesis and try to quantify the impact the mold line has on the field distribution, a 3D replica of the insulator was designed in a Computer Aided Design (CAD) software package (Figure 7) using the parameters of Table 1.

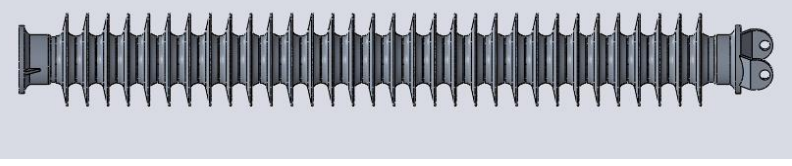

Figure 7: 3D insulator model.

Table 1. The design parameters of the insulators.

\begin{tabular}{|l|c|}
\hline \multicolumn{1}{|c|}{ Parameter } & Value \\
\hline Number of sheds & 32 \\
\hline Length of insulator $(\mathbf{m m})$ & 1675 \\
\hline Shed diameter $(\mathbf{m m})$ & 169 \\
\hline Shed Spacing $(\mathbf{m m})$ & 37 \\
\hline Core diameter $(\mathbf{m m})$ & 85 \\
\hline Leakage distance $(\mathbf{m m})$ & 3736 \\
\hline
\end{tabular}

To simulate the mold line, a $0.2 \mathrm{~mm}$ in diameter semicircular protrusion, running the entire length of the housing has been added to the model, see Figure 8.

The CAD model was then imported into COMSOL Multiphysics. A cylinder with a height of $2 \mathrm{~m}$ and a base of 1 $\mathrm{m}$ in diameter was added to represent the surrounding air and define the computation domain in Figure 9. After initial simulation runs it became evident that the large number of elements required to represent the entire model was prohibitive due to hardware limitations. It was therefore decided to simplify the model by retaining only the three sheds nearest to each end-fitting. Because of their proximity to the electrodes, these sheds are subjected to the highest electric field under

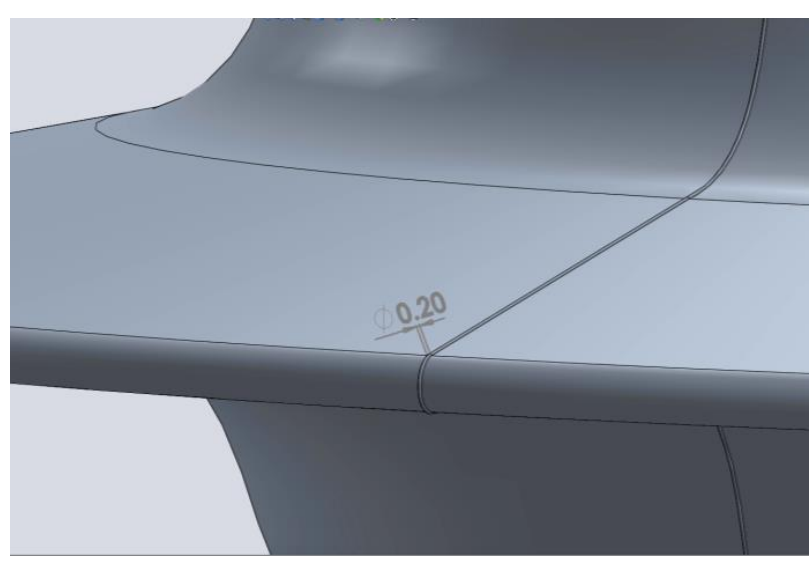

Figure 8: Mold line.

normal operating conditions. Additionally, the mold line was removed from one side of the insulator. This also made possible the direct comparison of the electric field distribution between the side with and the side without the mold line.

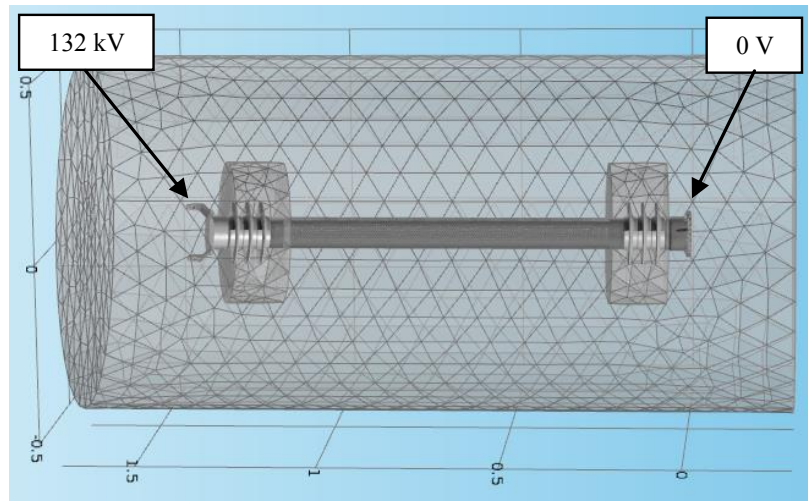

Figure 9: Computation domain.

The mesh parameters for the model are the following:

- No. of elements: 10415184

- Max. element size: $0.1 \mathrm{~m}$

- Min. element size: $40 \mu \mathrm{m}$

In order to achieve the required accuracy in the vicinity of the mold line and avoid sharp edges that could give erroneous results, the area was meshed much finer than the rest of the model, Figure 10. The mesh parameters for the mold line specifically are the following:

- No. of elements: 290856

- Max. element size: $80 \mu \mathrm{m}$

- Min. element size: $40 \mu \mathrm{m}$

The boundary conditions for the analysis were set as:

- $132 \mathrm{kV}$ applied on the high-voltage (HV) endfitting

- $0 \mathrm{~V}$ applied on the ground end-fitting

- zero charge applied (by default) on the exterior boundaries of the computation domain 


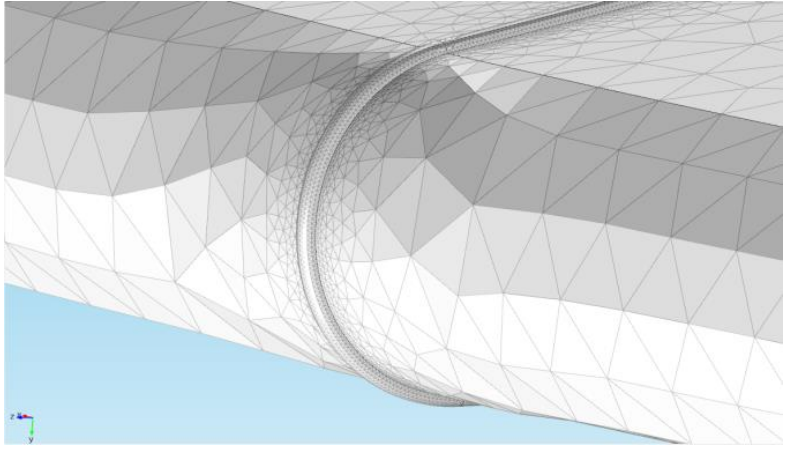

Figure 10: Mold line mesh.

The dielectric constants of the materials were set as follows:

$\begin{array}{lll}\text { - } & \text { EPDM (housing): } & 3.3 \\ \text { - } & \text { GRP (core): } & 2.4 \\ \text { - } & \text { Steel (end-fittings): } & 1 \\ \text { - } & \text { Air: } & 1\end{array}$

\section{B. Results}

Figure 11 shows the variation of the electric field magnitude on two virtual lines, one on either side of the insulator model, running through the three sheds closest to the $\mathrm{HV}$ end-fitting, $0.06 \mathrm{~m}$ from and parallel to the longitudinal axis of the unit. The electric field magnitude on the first shed (left) due to the presence of the mold line is increased from 3.10 to $4.75 \mathrm{kV} / \mathrm{cm}$, approximately $53 \%$ higher. The effect is present on the second and third sheds with an enhancement of $42 \%$ and $31 \%$ respectively.

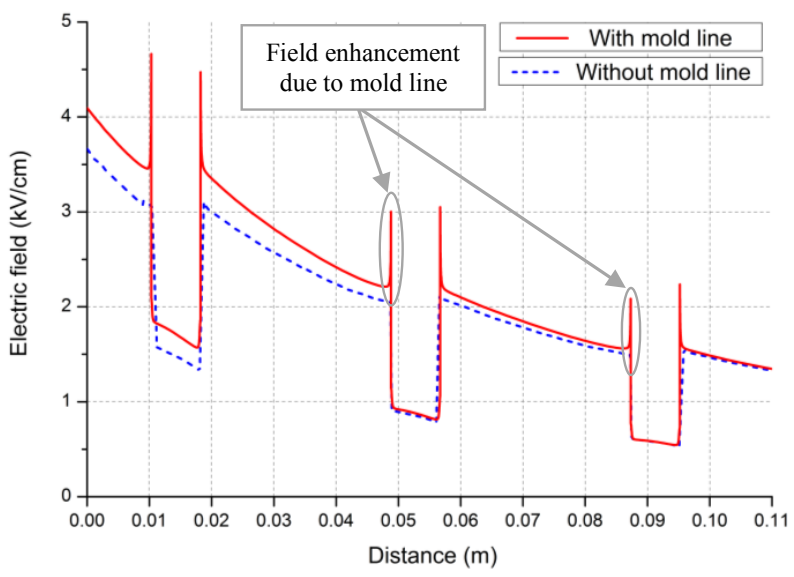

Figure 11: Electric field magnitude with and without the mold line.

The increase in the magnitude of the electric field is not limited to the side of the shed facing the HV end-fitting but is present on the other side as well. Furthermore, in the case of the first two sheds, the mold line affects the electric field distribution not only directly on top of the mold line but also in the area between the sheds. The aforementioned effects, albeit reduced, are also present on the ground end of the insulator.

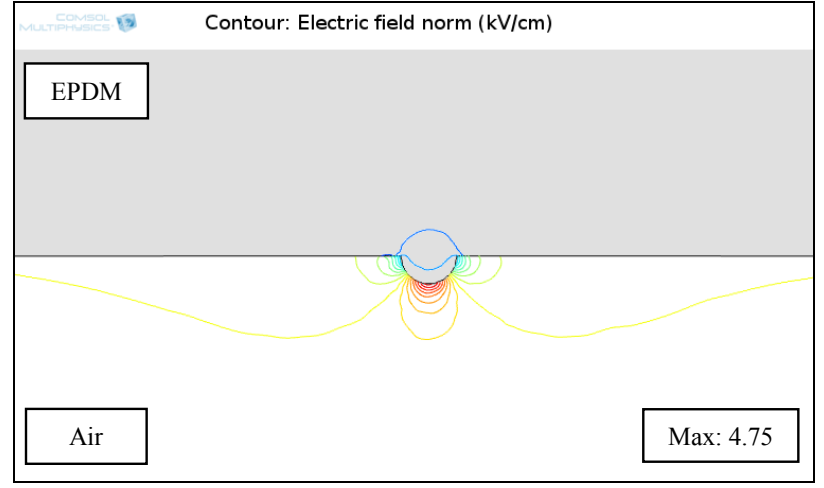

Figure 12: Electric field distribution with the mold line.

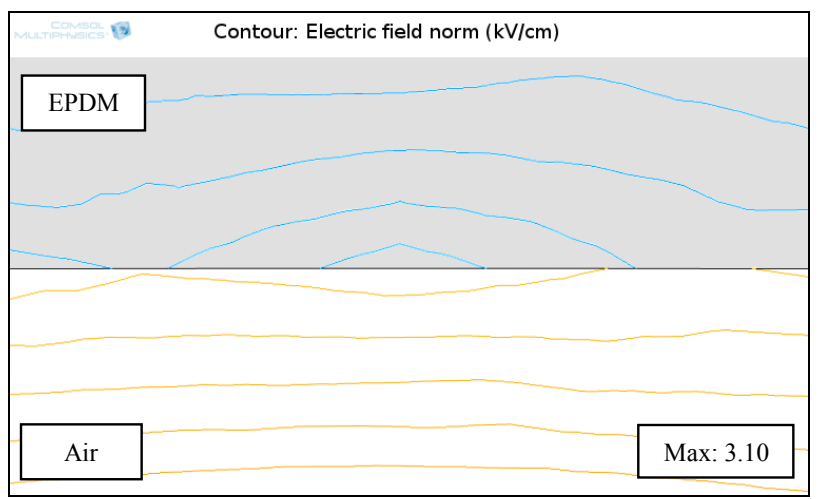

Figure 13: Electric field distribution without the mold line.

Figures 12 and 13 show the electric field distribution on the underside of the shed closest to the HV end-fitting, at the same locations as Figure 11, in the form of contour plots. Although the field magnitude is highest directly above the mold line, the areas on the left and right are also affected to a smaller degree. More importantly, the shape of the distribution in the absence of a mold line is uniform whereas the mold line distorts the field distribution in its immediate vicinity.

\section{DISCUSSION}

The mold line protrusion has been reported in literature [12] to appear as a weak point in an insulator's design. The electric field analysis of the jumper loop $132 \mathrm{kV}$ insulator shows that the presence of the mold line can significantly enhance the local electric field by more than $50 \%$. This enhancement is achieved just by the geometrical consideration of the mold line under dry condition. It is important to note however, that the model of the mold line used for the analysis is relatively ideal. In reality the shape of the mold line varies considerably both in shape and in size. The presence of sharp edges or deep ridges is not uncommon, see Figure 14. Moreover, the texture of the polymer on the mold line appears to be different than the rest of the surface, indicating that the material properties could differ. Furthermore, the study did not take into account the presence of pollution or water on the surface of the insulator. In [10] it was shown that the mold 
line can act as a gutter for the water to run down along the length of the insulator under precipitation. Thus, it is suggested that the widening of the hydrophilic light-colored strip surrounding the mold line on D1 side, see Figure 2 and 3, is due to a combination of high electric fields and water streams cleaning or not allowing the formation of dark colored pollution.

Although the field enhancement due to the mold line alone might not be able to create the discharge patterns observed on the insulator in Figures 2 to 4, the added contribution of the factors mentioned above could amplify the effect and contribute to the faster ageing of the surface.

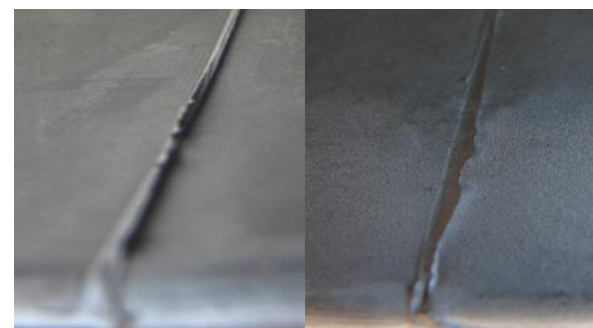

Figure 14: Extreme variations of the mold line shape; sharp peak at the left hand side; and a concave groove on the right hand side.

\section{CONCLUSIONS}

The ageing features observed on the $132 \mathrm{kV}$ jumper loop insulator could not be attributed solely to the presence of the mold line. Despite the fact that a uniform semicircular protrusion could enhance the local electric field upto 53\% under dry conditions, it is not sufficient to cause the surface discharges observed on the surface of the insulator. It is suggested that the environmental stresses at site and the weathering cycles have to contribute to ageing features observed at the insulators surface.

\section{REFERENCES}

[1] D. A. Swift, C. Spellman, and A. Haddad, "Hydrophobicity transfer from silicone rubber to adhering pollutants and its effect on insulator performance," IEEE Trans. Dielectr. Electr. Insul., vol. 13, pp. 820$829,2006$.

[2] T. Kikuchi, S. Nishimura, and M. Nagao, "Survey on the use of nonceramic composite insulators," IEEE Trans. Dielectr. Electr. Insul., vol. 6, pp. 548-556, 1999.

[3] C. Spellman, H. Young, A. Haddad, A. Rowlands, and R. Waters, "Survey of polymeric insulator ageing factors," Eleventh Int'l. Sympos. High Voltage Engineering (Conf. Publ. No. 467), 1999, vol. 4, pp. 160163.

[4] S. M. Rowland, J. Robertson, Y. Xiong, and R. Day, "Electrical and material characterization of field-aged $400 \mathrm{kV}$ silicone rubber composite insulators," IEEE Trans. Dielectr. Electr. Insul., vol. 17, pp. 375-383, 2010.

[5] A. Tzimas and S. M. Rowland, "Risk estimation of ageing outdoor composite insulators with Markov models," IET Generation, Transmission \& Distribution, 6(8), pp 803, 2012.

[6] Y. Xiong, S. M. Rowland, J. Robertson, and R. J. Day, "Surface analysis of asymmetrically aged $400 \mathrm{kV}$ silicone rubber composite insulators," IEEE Trans. Dielectr. Electr. Insul., vol. 15, pp. 763-770, 2008.

[7] R. Sundararajan, A. Mohammed, N. Chaipanit, and T. Karcher, "Inservice aging and degradation of $345 \mathrm{kV}$ EPDM transmission line insulators in a coastal environment," IEEE Trans. Dielectr. Electr. Insul., vol. 11, pp. 348-361, Apr. 2004.

[8] A. Tzimas, S. M. Rowland, and M. Queen, "Ageing Features of $132 \mathrm{kV}$ EPDM Insulators in Severe Polluted Environment," IEEE Trans. Dielectr. Electr. Insul., Under review, 2013

[9] "Average UK conditions," 2009. [Online]. Available: http://www.metoffice.gov.uk/climate/uk/ws/ .

[10] A. Tzimas and S. M. Rowland, "Asymmetrical ageing of composite insulators: Effect on water dripping behaviour and electrical performance,” IEEE Conf. Electr. Insul. Dielectr. Phenomena, 2010.

[11] STRI, "STRI Guide 1/92 Hydrophobicity Classification".

[12] E. A. Cherney, B. Biglar, and S. Jayaram, "Salt fog testing of polymer housed surge arresters," IEEE Trans. on Power Delivery, pp. 252-258, Apr. 2001. 